\title{
Male Infertility as a Circumstance of Discovery of Adult Cryptorchidism: A Retrospective Analysis from the Region of Thies
}

\author{
Yoro Diallo', Mama Sy Diallo², Saint Charles Kouka1, Adolphe Essomindedou Leloua1, \\ Amy Diame1, Modou Faye', Adamson Phiri' ${ }^{1}$, Cheikna Sylla1 \\ ${ }^{1}$ Department of Urology, Faculty of Health Sciences, University of Thiès, Thiès, Senegal \\ ${ }^{2}$ Laboratory of Cytogenetic and Reproductive Biology, University Teaching Hospital Aristide Le Dantec, Dakar, Senegal \\ Email:yorodiallo@hotmail.com,mamatasy@yahoo.fr, saintkouka@yahoo.fr, adolpheleloua11@gmail.com, \\ adamsonphiri@juno.com, aadiame@hotmail.com,csylla@orange.sn
}

How to cite this paper: Diallo, Y., Diallo, M.S., Kouka, S.C., Leloua, A.E., Diame, A., Faye, M., Phiri, A. and Sylla, C. (2017) Male Infertility as a Circumstance of Discovery of Adult Cryptorchidism: A Retrospective Analysis from the Region of Thies. Open Journal of Urology, 7, 124-130.

https://doi.org/10.4236/oju.2017.78015

Received: June 6, 2017

Accepted: August 15, 2017

Published: August 18, 2017

Copyright $\odot 2017$ by authors and Scientific Research Publishing Inc. This work is licensed under the Creative Commons Attribution International License (CC BY 4.0).

http://creativecommons.org/licenses/by/4.0/

\begin{abstract}
Introduction: The aim of this work is to study the clinical aspects and the impact of cryptorchidism on male infertility in the region of Thies. Patients and methods: This is a retrospective study involving 28 patients followed up at the Saint Jean de Dieu, Barthimée and Tivaouane hospitals of the region of Thies between January 2007 and December 2016. Results: Among the 223 patients followed up for the undescended testicle, $13 \%(n=28)$ were adults or at least 15 years old. $71 \%(n=20)$ were married. Fourteen patients were followed up for primary infertility lasting for a period of time averaging 7 years. The mean age of the patients was 28 years (range: 17 years and 45 years). Cryptorchidism was unilateral in $82 \%(\mathrm{n}=23)$ and bilateral in $18 \%(\mathrm{n}=5)$. The mean delay of consultation varied from 1 to 13 years. The main reason for consultation was couple infertility (50\%). The semen analysis was requested in all our patients. The levels of FSH, LH and testosterone were measured by immunoassay for the patients with azoospermia $(n=9)$. We noticed 2 cases of hypotestosteronemia and 3 cases of increased FSH serum level. Computed Tomography scans (CT) were performed in $28.5 \%$ of patients $(n=8)$ and ectopic testicles were found very high in the inguinal area in 5 cases. The open inguinal approach was used. In perioperative period, the testicle was found, high in the inguinal region in 5 patients (17.8\% of the cases) and low in inguinal region in 19 patients $(67.8 \%)$. In 4 cases the testicle was in abdominal position. The testicle was atrophied in $53.5 \%$ of the patients $(n=15)$ and 8 patients presented testicular hypotrophy. An orchidectomy was performed in 1 patient in whom it was impossible to lower the atrophied testicle. The postoperative period was uneventful and simple. The mean follow-up duration after the operation was 36 months (12 - 60 months).
\end{abstract}




\section{Keywords}

Cryptorchidism, Adult, Azoospermia, Semen Analysis, Infertility

\section{Introduction}

Cryptorchidism is the non-descent of the testicle which is permanently located outside the scrotum. It is a congenital condition and its diagnosis is easily suspected whenever the scrotum is empty. The circumstances of discovery are early in childhood. In that period, the surgical procedure is easier with very good results [1]. Therefore, the majority of studies are devoted during this period. However, in some situations, cryptorchidism may go unnoticed and show up in adulthood. In this context, the prognosis of testicular function and its impact on spermatogenesis can be really compromised [2]. Because the result of the surgery remains hypothetic, indeed, the procedure is more difficult and when the lowering is not possible, the other options can be the orchiopexy or orchiectomy because of severe hypotrophia or atrophia with alteration of the exocrine function [3]. The aim of this work is to study the clinical aspects and the impact of adult cryptorchidism on male infertility in the region of Thies.

\section{Patients and Methods}

This is a retrospective study conducted over a period of 10 years between January 2007 and December 2016, following data collection from 28 patients being followed up at the 3 hospitals of the area of Thies: Saint Jean de Dieu hospital, Barthimée de Thies and the Abdoul Aziz Dabakh hospital of Tivaouane. Included in this study were adult patients aged 15 years and older with unilateral or bilateral cryptorchidism and spermiogram. Excluded Patients included those aged less than 15 years, or with varicocele, or had a history of inguinal hernia or testicular surgery. The parameters were collected from the medical files of the patients followed up for infertility in Urology unit; Data concerning age, occupation, marital status, medico-surgical history, reasons and time to consultation, semen analysis results, medical imaging, surgical modalities and progress under treatment were analyzed. Patients benefited from inguinal open surgery consisting of testicular lowering followed by orchidopexy in dartos or orchiodectomy. Oral treatment with antioxydants was administrated to the patients after the surgery for 2 months to enhance the semen (Vitamin E, Zinc, Selenium). A semen analysis was performed in all patients 3 or 6 months after surgical cure. The study was approved by the ethical committee of Thies University.

\section{Results}

Out of a total of 223 patients followed up for the undescended testicle, 13\% ( $\mathrm{n}=$ 28) of the patients were adults aged at least 15 years (Figure 1). 


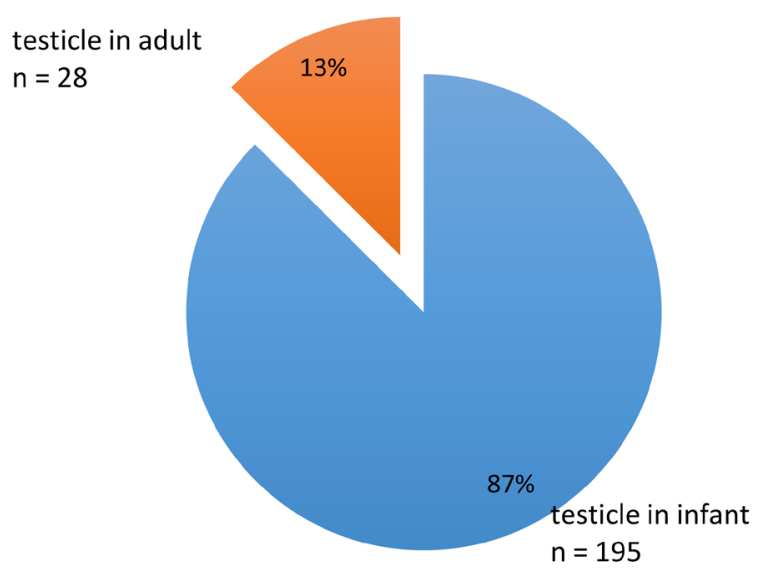

Figure 1. The distribution of cryptorchidism in adults.

Seventy-one point four percent $(n=20)$ were married. Fourteen patients were followed up for primary infertility lasting for a period of time averaging 7 years (range 1 - 13 years). The mean age of the patients was 28 years (range: 17 years and 45 years). Medical history revealed a unilateral cryptorchidism in 3 patients. The average delay consultation time varied from 1 to 13 years. The main reason for consultation was couple infertility (50\%), followed by the observation of scrotal vacuity by the patient himself in $14.3 \%$ of the cases (Table 1 ).

Cryptorchidism was unilateral in $82 \%(\mathrm{n}=23)$ of patients and bilateral in $18 \%$ $(\mathrm{n}=5)$. Concerning unilateral cryptorchidism, 14 patients presented it on the right versus 9 on the left. Physical examination revealed a testicle in $60.7 \%$ of patients $(n=17)$ and not palpable in 13 patients. One patient presented with hydrocele and testicular hypotrophy in 5 patients. No patient had an ectopic testicle. The semen analysis was requested in all our patients and allowed to objectify the results indicated in Table 2 .

The levels of FSH, LH and testosterone were measured by immunoassay for the Patients with azoospermia $(\mathrm{n}=9)$. It showed a decrease in testosteronemia in 2 patients, an increase in FSH in 3 patients, and in 4 patients the testosterone, FSH and LH levels were normal. Pelvic or scrotal ultrasound was performed in all our patients. The presence of a testicle high in the inguinal region was noted in 2 patients and a contralateral varicocele was observed in 6 patients. Computed tomography scans $(\mathrm{CT})$ were performed in $28.5 \%$ of patients $(\mathrm{n}=8)$ and undescended testicles were found very high in the inguinal area in 5 cases. However, it could not identify testicles in 3 cases. Concerning management, the open surgical inguinal approach was used in all our patients. In the perioperative period, the testicle was situated high in the inguinal area in 5 patients (17.8\%) of the cases, low inguinal area in 19 patients or $67.8 \%$, while 4 patients presented with testicles in the abdominal position. In 6 patients, it was impossible to pull down the testicle into the scrotum. In the bilateral forms, the cure was carried out in a single operation. Three patients required a second surgical procedure to complete the reduction over a period varying between 3 to 5 years. The testicle was atrophied in $53.5 \%$ of the patients $(n=15)$ and 8 patients had testicular hypotrophy. 
Table 1. The different reasons for consultation.

\begin{tabular}{ccc}
\hline Reason for consultation & Number & Percentage (\%) \\
\hline Scrotal vacuity & 4 & 14.3 \\
Couple infertility & 14 & 50 \\
Inguinal swelling & 3 & 10.7 \\
Pelvic pain & 2 & 7.1 \\
Others & 5 & 17.9 \\
Total & 28 & 100 \\
\hline
\end{tabular}

Table 2. Distribution of patients according to the results of semen analysis.

\begin{tabular}{ccc}
\hline Semen analysis & Number of patients & Percentage (\%) \\
\hline Light and Moderate Astheno-teratozoospermia & 10 & 35.8 \\
Severe oligospermia & 5 & 17.8 \\
Azoospermia & 9 & 32.1 \\
Astheno-teratozoospermia necrospermia & 4 & 14.3 \\
Total & 28 & 100 \\
\hline
\end{tabular}

An orchiectomy was performed in 1 patient in whom it was impossible to pull down the atrophied testicle into the scrotum. None of the patients presented with malignant degeneration of acryptorchidic testicle. The postoperative period was uneventful and simple with no complications noted in our patients. The mean follow-up duration after the operation was 36 months (12 - 60 months). We observed a marked improvement in the spermogram for 13 patients. Three of them have a child. We did not record cases of malignant degenerative on the cryptorchid testis or lowered our study.

\section{Discussion}

Cryptorchidism is a common congenital disorder accounting for about $1 \%$ to $3 \%$ of all urogenital malformations [2]. However, its incidence decreases with age, it is estimated in adults to be about $0.23 \%$ to $0.28 \%$ [1] [4]. There is little epidemiological data on cryptorchidism in adults [1].

Its mechanism of occurrence is not completely elucidated, various theories including hormonal (androgens) and anatomical (gubernaculum testicle) have been advanced [4]. Elsewhere, Damgaard [5] incriminated the role of intra-uterine insemination and the use by the mother of nicotinic derivatives in the mechanism of occurrence of cryptorchidism.

Unilateral forms are more frequent at about $80 \%$ against $20 \%$ for bilateral forms [6]. In our study, cryptorchidism was predominantly right sided, unlike Jeddou [7] who encountered a slight left predominance. Sallami [1] states that the incidence from side to side is not significant.

The diagnosis is usually easy before an empty scrotum from birth. Yet this obvious situation contrasts the high rate of patients reporting not being aware of 
the situation up until the time of an assessment for a couple's infertility or for military or corporate recruitment. However, half of the patients acknowledged that they had neglected this condition for a long time because they were completely unaware of the repercussions of this condition. Ismail [8] had identified nearly $1 / 3$ of the patients claimed to have discovered during a physical examination of military service or for infertility of the couple. Para clinic explorations are of indicated in the event of an undescended testicle search during a clinical examination or in association with extended physical examination in case of other associated congenital malformations and the context of general surveillance [9].

The late discovery of cryptorchidism in adults exposes the problem of screening and the risks of potential complications including infertility and malignant degeneration. Indeed, the risk increases with age and it is not modified by the orchidopexia [10].

Hormone therapy is indicated during the first years of life; therefore, it does not find its place in the management of adults. Surgery remains the basic treatment. The preservation or not of the cryptorchidic testicle for adults is diversely appreciated. Indeed, some authors like Kucheria [11] propose a preventive orchidectomy in case of unilateral cryptorchidism due to the increased risk of degeneration and torsion. Authors such as Mathers [12] recommended keeping and monitoring the undescended testicle. It should be noted that the semen analysis is all the more altered as the testicle is elevated or pull down late [13]. In such cases it is advisable to propose an orchidectomy or conservative surgery, taking into account the degree of alteration of the semen analysis and the location of the undescended testicle. Thus, orchidectomy is indicated in cases of high testicular localization with a highly altered spermiogram.

The parameters of the semen analysis are often perturbed in patients with cryptorchidism in adulthood and even more frequent in cases of bilateral cryptorchidism [1] [14]. According to Saenger [4], the fertility rate is inversely correlated with the age of the intervention. The higher the age of the intervention, the more irreversible and severe are the lesions. It is in this context that a semen analysis should be systematically performed to assess the effect on the reproductive function. It is clear from the work of most authors that cryptorchidism, even one-sided, is a factor that should be taken into account in the causes of infertility [12].

Malignant degeneration is a real complication. Indeed, Darzi [15] had estimated $10 \%$ of testicular tumors occurring on cryptorchidic terrain. Chilvers [16] even suggests an absolute risk of developing testicular cancer at $1 \%$. Seung [17] has been noted that a late operation for undescended testis is associated with an increased risk of testicular malignancy and infertility. In the literature, the delay of degeneration after orchidopexy is diversely appreciated. Thus, this period varies from 15 years according to Swerdlow [18] to 29.4 years according to Toledano [19] between 20 and 49 years. Dysgenesis of the gonad, irreversible even after pulling down the testicle and orchidopexia, are at the origin of the tumors [20]. In all cases, it is recommended to lower the testicle to improve spermato- 
genesis but to monitor for possible malignant degeneration [21].

\section{Conclusion}

Cryptorchidism in adults presents a real risk for causing infertility. Therefore, close monitoring is required even after orchidopexy. It has a significant impact on the status of the individual's fertility. Better prevention is required by systematic neonatal examination, parental awareness and surgical cure in the first years of life.

\section{Conflict of Interest}

There is no conflict of interest.

\section{References}

[1] Sallami, S., Rhouma, S.B., Monia, T., Rebai, S., Cherif, K., Nidhammedine, K., et al. (2011) La Cryptorchidie de l'Adulte: Aspects Cliniques et Thérapeutiques. A Propos de 100 Cas. Tunisie Medicale, 89, 254-257.

[2] Chung, E. and Brock, G. (2011) Cryptorchidism and Its Impact on Male Fertility: A State of Art Review of Current Literature. Canadian Urological Association Journal, 5, 210-214. https://doi.org/10.5489/cuaj.1010

[3] Dada, R., Gupta, N.P. and Kucheria, K. (2002) Case Report. Cryptorchidism and AZF Microdeletion. Asian Journal of Andrology, 4, 148.

[4] Saenger, P. and Reiter, E.O. (1992) Management of Cryptorchidism. Trends in Endocrinology \& Metabolism Tem, 3, 249-253. https://doi.org/10.1016/1043-2760(92)90126-L

[5] Damgaard, I.N., Jensen, T.K., Petersen, J.H. and Skakkebæk, N.E. (2007) Cryptorchidism and Maternal Alcohol Consumption during Pregnancy. Environmental Health Perspectives, 115, 272-277. https://doi.org/10.1289/ehp.9608

[6] Spencer, J.R. (1994) The Endocrinology of Testicular Descent. American Urological Association Update Series Lesson, 12, 94-99.

[7] Jeddou, B.F., Ghozzi, S. and Rais, N.B. (2005) La Cryptorchidie de l'Adulte: A Propos de 81 Cas. Tunisie Medicale, 83, 742-745.

[8] Ismail, T.O., Jira, H., Janane, A., Qarro, A., Chafiki, J., Sossa, J., et al. (2010) Testicule non Descendu en Post-Puberté: Orchidopexie ou Orchidectomie? A Propos d'une Revue de la Littérature. JMaroc Urol, 18, 11-13.

[9] Marchetti, F., Bua, J., Tornese, G., Piras, G., Giacomo, T.G. and Ronfani, L. (2012) Management of Cryptorchidism: A Survey of Clinical Practice in Italy. BMC Pediatrics, 12, 4. https://doi.org/10.1186/1471-2431-12-4

[10] Touiti, D., Ameur, A., Beddouch, A., Oukheira, H. and Taobane, H. (2001) Place de la Cœlioscopie dans l'Exploration et le Traitement des Testicules Impalpables chez l'Adulte. À Propos de Deux Observations. Urology Annals, 35, 353-355. https://doi.org/10.1016/S0003-4401(01)00059-6

[11] Kucheria, R., Sahai, A., Sami, T.A., Challacombe, B., Godbole, H., Khan, M.S. and Daspupta, P. (2005) Laparoscopic Management of Cryptorchidism in Adults. European Urology, 48, 453-457. https://doi.org/10.1016/j.eururo.2005.04.008

[12] Mathers, M.J., Sperling, H., Rübben, H. and Roth, S. (2009) The Undescended Testis: Diagnosis, Treatment and Long-Term Consequences. Deutsches Arzteblatt In- 
ternational, 106, 527-532.

[13] Hodziseli, F., Girard, J., Höcht, B., Von der Ohe, M. and Stalder, G. (1980) Effects of LH-RH Treatment on Hypothalamo-Pituitary-Gonadal Axis and Leydig Cell Ultrastructure in Cryptorchid Boys. Hormone Research, 13, 358-366. https://doi.org/10.1159/000179304

[14] Hadziselimovic, F. (2002) Cryptorchidism, Its Impact on Male Fertility. European Urology, 41, 121-123. https://doi.org/10.1016/S0302-2838(01)00040-9

[15] Darzi, A.A., Aliramaji, A. and Ramezani, M.S. (2010) Unresolved Abdominal Mass in an Adult Cryptorchid Testis: A Case Report. International Journal of General Medicine, 3, 395-398.

[16] Chilvers, C. and Pike, M.C. (1989) Epidemiology of Undescended Testis. In: Oliver, R.T., Blandy, J.P. and Hope-Stone, H.F., Eds., Urological and Genital Cancer, Blackwell Scientific, Oxford, 306-321.

[17] Seung, C.J., Lee, S., Ku, J.Y. and Lee, S.D. (2014) Clinical Characteristics and Treatment of Cryptorchidism in Adults: A Single Center Experience. World Journal of Men's Health, 32, 110-115. https://doi.org/10.5534/wjmh.2014.32.2.110

[18] Swerdlow, A.J., Higgins, C.D. and Pike, M.C. (1997) Risk of Testicular Cancer in Cohort of Boys with Cryptorchidism. BMJ, 314, 1507-1511. https://doi.org/10.1136/bmj.314.7093.1507

[19] Toledano, M.B., Jarup, L., Best, N., Wakefield, J. and Elliott, P. (2001) Spatial Variation and Temporal Trends of Testicular Cancer in Great Britain. British Journal of Cancer, 84, 1482-1487. https://doi.org/10.1054/bjoc.2001.1739

[20] Ferguson, L. and Alexander, I.A. (2013) Testicular Cancer and Cryptorchidism Frontiers. Endocrinology, 4, 1-9.

[21] Hermanowicz, A., Matuszczak, E., Wojciech, D., Koronkiewicz, D.E., Komarowska, M., Oksiuta, M., et al. (2012) Expression of Estrogen Receptors A and B in Paratesticular Tissues in Boys Operated on for Unilateral Cryptorchidism between the 1st and 4th Years of Life. Medical Science Monitor, 18, 630-634.

https://doi.org/10.12659/MSM.883490

Submit or recommend next manuscript to SCIRP and we will provide best service for you:

Accepting pre-submission inquiries through Email, Facebook, LinkedIn, Twitter, etc. A wide selection of journals (inclusive of 9 subjects, more than 200 journals)

Providing 24-hour high-quality service

User-friendly online submission system

Fair and swift peer-review system

Efficient typesetting and proofreading procedure

Display of the result of downloads and visits, as well as the number of cited articles

Maximum dissemination of your research work

Submit your manuscript at: http://papersubmission.scirp.org/

Or contact oju@scirp.org 